\title{
ORAL HEALTH STATUS AND TREATMENT NEEDS AMONG RESIDENTS OF ORPHANAGES IN PANCHKULA DISTRICT, HARYANA, INDIA
}

\author{
Mohit Bansal $^{1}$, K L Veeresha ${ }^{2}$, Navdeep Kaur Walia \\ ${ }^{1}$ Reader, Department of Public Health Dentistry, Swami Devi Dyal Hospital \& Dental College, Haryana, India \\ ${ }^{2}$ Professor, Department of Public Health Dentistry, M.M. College of Dental Sciences and Research, Haryana, India \\ ${ }^{3}$ Reader, Department of Public Health Dentistry, BJS Dental College and Hospital, Punjab, India
}

\begin{abstract}
Objective: To assess the oral health status and treatment needs among residents of orphanages in Panchkula district. Materials and Methods: A cross-sectional study was conducted at 11 orphanages of Panchkula District in which all the 464 subjects aged 4-26 years were examined. A Modified WHO format (1997) was used to record the oral health status and demographic details. The inmates needing the treatment were treated up to the best possible extent. Results: The prevalence of dental caries in permanent dentition was found to be $22.7 \%$ while for the primary dentition was $5.73 \%$. The mean DMFT was 1.01 whereas the mean dft was $0.28 .58 .1 \%$ had healthy periodontium, $28 \%$ had CPI score 2 followed by $13.6 \%$ who had CPI score $1.16 .4 \%$ subjects had various grades of dental fluorosis. $56.7 \%$ of the subjects had never visited a dental surgeon. Conclusion: The results from this baseline study indicate that the prevalence of dental diseases is high among orphans. They have many cumulative treatment needs and very poor access to oral health care. Therefore, educational programs are to be initiated for the orphans regarding causes, prevention and treatment of dental diseases. It is crucial to generate considerable efforts to implement health promotion strategies to reverse the observed trends and to provide treatment to dental problems to prevent their biologic and psychological consequences.
\end{abstract}

Key words: Oral health, Treatment needs, Dental caries, Orphans.

\section{INTRODUCTION}

Oral health is a vital component of general health, which contributes to each individual's mental well being, quality of life, physical appearance and interpersonal relationship. Dental caries is an important dental public health problem and is the most prevalent oral diseases among children in the world. ${ }^{1}$

The children of a nation are supremely important assets. They are born to be happy but many of them are in a state of misery due to strange quirks of their fate in the form of personal tragedies. Further, they become socially handicapped and thus opportunity for healthy personality development and full unfolding of potentialities are hampered by certain elements such as parental inadequacy or their loss. ${ }^{2}$
Early family deprivation makes the child devoid of stimulation, normal care and interpersonal interaction. In the orphanages the child experiences detachment and psychological insecurity. Thus the child starts to feel lonely in his life. ${ }^{3}$ This leads to neglect of personal care and hence may also lead to poorer oral health.

As per the data collected from various sources the total number of orphanages in India is $763 .{ }^{4}$ According to UNICEF there are about 25,000,000 orphans in India. ${ }^{5}$ Hence, it becomes the duty of everyone in the society to share their resources and to elevate such individuals from distress and as professionals it is our moral responsibility to render professional help to them.

As to the best of our knowledge there are no study reports regarding the oral health status and treatment needs of 
such children at orphanages, the current study was taken up on the inmates orphanages of Panchkula district, to explore and suggest the best possible approach for oral health care delivery to such children.

\section{MATERIALSAND METHOD}

Data collection-

A cross- sectional survey was carried out in all the 11 orphanages of Panchkula district, Haryana. 464 orphans ( 210 boys and 254 girls) aged 4-26 years were included in the study. The study was conducted from May 2009 to September 2009.

Permission for study was obtained from the Director Social and Welfare Department Panchkula (Haryana). The examination was conducted after due calibration of the investigator. The ethical clearance was taken from the ethical board committee of Maharishi Markandeshwar University, Mullana. Each orphanage was visited after taking the prior permission from the concerned authorities. The examination was conducted by a single calibrated examiner using mouth mirror, explorer and adequate light. The trained recording assistant was made to sit close enough to the examiner to record the data. The data regarding the demography, oral health status and treatment needs of the inmates were recorded on a modified WHO format 1997. ${ }^{6}$ Each assessment camp was followed by dental treatment and health education camp.

Statistical Analysis-

The data's were analyzed using SPSS version 13.0. Chi square analysis was used to find the significance of the cross-tabulation of counts of two or more variables. Student $t$-test (Unpaired) and analysis of variance (ANOVA) were used to find the significance of the cross-tabulation of a variable with the mean of another variable.

\section{RESULTS}

The mean age of subjects was 12.2 years. $45.3 \%$ were males and $54.7 \%$ were females (Table 1 ).

Age wise distribution of subjects shows that 26.3\% (122) subjects were in the age group 4-9 years, 54.1\% (251) were in the age group 10-15 years, $15.3 \%$ (71) were in the 16-20 years age group and 4.3\% (20) were in the age group of 21-26 years.
Table 1: Age and Sex distribution of subjects

\begin{tabular}{|l|lc|lr|rr|}
\hline Age & \multicolumn{2}{|c|}{ Males } & \multicolumn{2}{c|}{ Females } & \multicolumn{2}{c|}{ Total } \\
& No. & $\mathbf{\%}$ & \multicolumn{2}{|c|}{ No. } & $\mathbf{\%}$ & \multicolumn{2}{c|}{ No. } & \% \\
\hline 4-9 years & 54 & 25.7 & 68 & 26.7 & 122 & 26.3 \\
\hline 10-15 years & 116 & 55.2 & 135 & 53.1 & 251 & 54.1 \\
\hline 16-20 years & 34 & 16.1 & 37 & 14.1 & 71 & 15.3 \\
\hline 21-26 years & 6 & 2.8 & 14 & 5.5 & 20 & 4.3 \\
\hline Total & 210 & 45.2 & 254 & 54.7 & 464 & 100 \\
\hline
\end{tabular}

Education qualification shows that 9.7\% (45) do not go to school, $10.8 \%$ (50) were in kindergarden $37.1 \%$ (172) were pertaining primary school education, $36 \%$ (167) were pertaining high school education, 5.6\% (26) were pertaining secondary school education and only $0.9 \%$ (4) were undergraduates.

$26.3 \%$ of the subjects reported to have one or the other dental problem. The most common complaint among the subjects was of tooth pain, followed by bleeding from gums and decay in teeth (Figure 1). Majority of them had dental problems since months (Table 2).

Table 2: Distribution of subjects with duration of tooth problem

\begin{tabular}{|l|c|c|}
\hline Duration & Percentage & Frequency \\
\hline$<7$ days & 4.1 & 19 \\
\hline Upto one month & 6.3 & 29 \\
\hline one month- one year & 13.8 & 64 \\
\hline Total & 26.3 & 122 \\
\hline
\end{tabular}

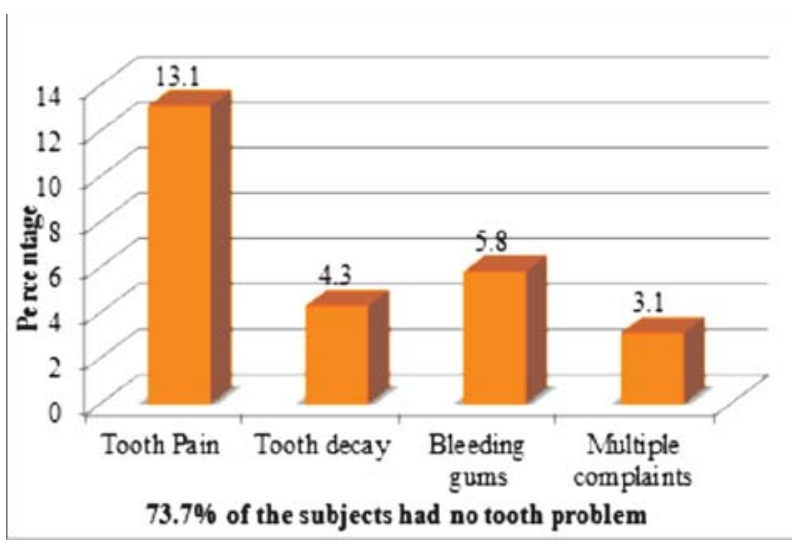

Figure 1: Type of tooth complaint

$0.6 \%$ of the subjects were not using any oral hygiene maintenance aid while the rest used toothbrush to clean their teeth. $55 \%$ of the subjects did not clean their tongue; $31.7 \%$ used tooth brush and only $13.4 \%$ of the subjects used tongue cleaner to clean their tongue. $65.9 \%$ of the subjects brushed their teeth once daily. 
The prevalence of dental caries in permanent dentition was found to be $22.7 \%$ while for the primary dentition it was $5.73 \%$. The mean DMFT was 1.01 (males-1.06 and females- 0.96) whereas the mean dft was 0.28 (males0.38 and females- 0.18) (Figure 2). As age advanced the prevalence of dental caries increased.

$6.89 \%$ subjects could not be considered for CPI recording as only primary teeth were present. In the rest of the sample, $58.1 \%$ of the subjects had healthy periodontium, and $41.9 \%$ had different CPI scores. The female subjects were affected more than males showing statical significance (Table 3) $\{\mathrm{p}$ value $<0.001\}$.It was seen that the CPI score increased as age advanced (Table 4).

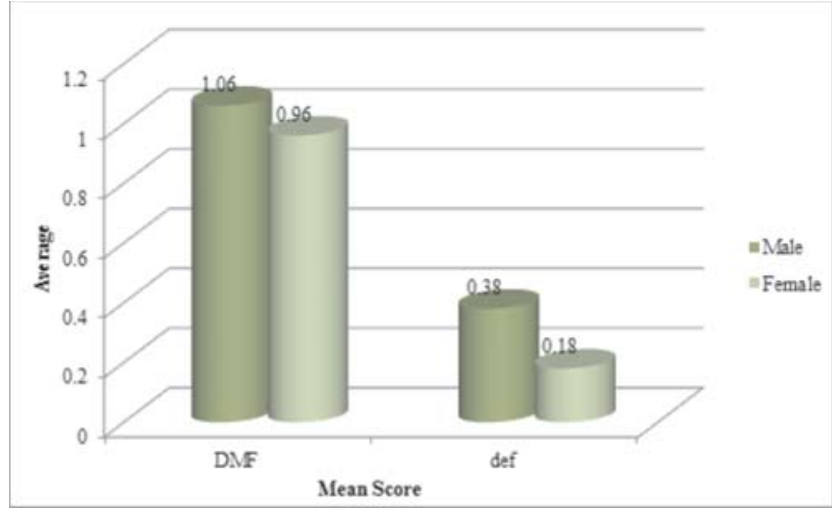

Figure 2: Showing gender wise mean DMF and def
$16.4 \%$ subjects had various grades of dental fluorosis (Table 5), while $83.6 \%$ of the subjects had no fluorosis.

\section{DISCUSSION}

It is unfortunate that in earlier days the inmates of orphanages are used for experimental studies. However, the reports regarding the oral health status and treatment needs of inmates of orphans are less when compared to other population groups. However few good study reports are taken for comparison.

Female to male ratio in our study was high similar to the finding by Mazhari F. Ajami B and Ojrati $\mathrm{N}(2008){ }^{7}$. The reason for this could be that females $(54.7 \%)$ are still considered a burden on the society and hence comprise a major part of the inmates normally found in orphanages.

$26.3 \%$ of the subjects were in the age group of 4-9 years. This can be due to fact that due to early loss of their parents they are voluntary left in these orphanages by their relatives or are adopted by government institutions.

Majority of the subjects were school going and pertaining to primary school This can be due to the reason that the government has now introduced a new rule that every child must be educated and the expenditure for these children is borne by the government itself.

Table 3: Comparison of Gender with Maximum CPI score per subject

\begin{tabular}{|c|c|c|c|c|c|c|c|c|c|c|}
\hline \multirow[t]{2}{*}{ Gender } & \multicolumn{2}{|c|}{$\begin{array}{l}\text { Healthy } \\
\text { (Score 0) }\end{array}$} & \multicolumn{2}{|c|}{$\begin{array}{l}\text { Bleeding } \\
\text { (Score 1) }\end{array}$} & \multicolumn{2}{|c|}{$\begin{array}{l}\text { Calculus } \\
\text { (Score 2) }\end{array}$} & \multicolumn{2}{|c|}{$\begin{array}{c}\text { 4-5mm Pocket } \\
\text { (Score 3) }\end{array}$} & \multicolumn{2}{|c|}{ Total } \\
\hline & $\%$ & $\mathbf{N}$ & $\%$ & $\mathbf{N}$ & $\%$ & $\mathbf{N}$ & $\%$ & $\mathbf{N}$ & $\%$ & $\mathbf{N}$ \\
\hline Male & 64.4 & 125 & 10.3 & 20 & 25.2 & 49 & 0 & 0 & 44.9 & 194 \\
\hline Female & 52.9 & 126 & 16.3 & 39 & 30.2 & 72 & 0.42 & 1 & 55.1 & 238 \\
\hline & 58.1 & 251 & 13.6 & 59 & 28 & 121 & 0.23 & 1 & 100 & 432 \\
\hline Number 0 & subject & ot re & $\mathrm{ded}=$ & & & & & & & \\
\hline Total (n) & $432+$ & $=464$ & & & & & & & & \\
\hline
\end{tabular}

Table 4: Showing comparison of Age with Maximum CPI score

\begin{tabular}{|c|c|c|c|c|c|c|c|c|c|c|c|c|c|}
\hline \multirow{2}{*}{$\begin{array}{c}\text { Age } \\
\text { group }\end{array}$} & \multicolumn{2}{|c|}{ Healthy } & \multicolumn{2}{|c|}{ Bleeding } & \multicolumn{2}{|c|}{ Calculus } & \multicolumn{2}{|c|}{ Pockets 4-5mm } & \multicolumn{2}{|c|}{ Pockets $>=6 \mathrm{~mm}$} & \multicolumn{2}{|c|}{ Not Recorded } & \multirow{2}{*}{$\begin{array}{c}\text { Total } \\
\text { Number }\end{array}$} \\
\hline & $\%$ & No. & $\%$ & No. & $\%$ & No. & $\%$ & No. & & No. & $\%$ & No. & \\
\hline $4-9$ & 58.1 & 71 & 8.19 & 10 & 7.37 & 9 & 0 & 0 & 0 & 0 & 26.2 & 32 & 122 \\
\hline $10-15$ & 57.7 & 145 & 14.7 & 37 & 27.4 & 69 & 0 & 0 & 0 & 0 & .0 & 0 & 251 \\
\hline $16-20$ & 38.02 & 27 & 15.4 & 11 & 45.07 & 32 & 1.4 & 1 & 0 & 0 & .0 & 0 & 71 \\
\hline $21-26$ & 40 & 8 & 5 & 1 & 55 & 11 & 0 & 0 & 0 & 0 & .0 & 0 & 20 \\
\hline Total & 58.1 & 251 & 13.6 & 59 & 28 & 121 & 0.23 & 1 & 0 & 0 & 6.89 & 32 & 464 \\
\hline
\end{tabular}


Table 5 Incidence of Dental fluorosis among subjects according to Modified Dean's Fluorosis Index

\begin{tabular}{|l|l|l|}
\hline Fluorosis Grade & Percentage & Frequency \\
\hline Normal & 83.6 & 388 \\
\hline Questionable & 9.9 & 46 \\
\hline Very mild & 5.0 & 23 \\
\hline Mild & 1.3 & 6 \\
\hline Moderate & 0.2 & 1 \\
\hline Total & 100.0 & 464 \\
\hline
\end{tabular}

The mean DMFT in the present study was similar to the results showed by Singh AA (1999) ${ }^{8}$ and Suher T, Dickson JP and Hadjimarkos DM. (1954). ${ }^{2}$ Some studies showed a higher DMFT than the present study, such as studies by Damle SG and Patel AR $(1994)^{9}$ in which the DMFT score ranged from 3.64.This difference in the DMFT may be attributed to the difference in the age group of the subjects examined and the type of feeding habits of the subjects. The prevalence of dental caries was found to be $28.4 \%$ which was less as reported by Aukland $\mathrm{S}$ and Bjelkaroey J $(1982)^{10}$ and Singh AA (1999). ${ }^{8}$

In the present study $58.1 \%$ subjects exhibited healthy periodontium. This was quite similar to the finding by Diangelis A.J and Rojas A.J (1982) ${ }^{11}$ in which $60.8 \%$ of the subjects had healthy periodontium. In the present study females exhibited high percentage of gingivitis and calculus than males which was inversely to the finding by Srivastava RP (1989). ${ }^{12}$

Majority of the subjects had never visited a dental surgeon despite having dental problems.

Therefore regular oral health screening camps should be made mandatory in such institutions.

\section{CONCLUSION}

Oral health education and oral health care programmes should be established in such institutions to influence the oral health behavior of the children and to avoid further deterioration in their oral health. The government should appoint a permanent doctor medical as well as dental in every institute so as to prevent and rehabilitate every individual from adverse consequences of any disease.

\section{ACKNOWLEDGEMENT}

The authors thank the orphanage authorities and the children who participated in this study for their co-operation. The authors report no conflict of interest.

\section{REFERENCES}

1) Saravanan S, Madivanan I, Subashini, Felix J. Prevalence pattern of dental caries in the primary dentition among school children. J Dent Res 2005; 16:140-6

2) Suher T, Dickson JP and Hadjimarkos DM. Caries experience among institutionalized children in the Pacific Northwest. J Dent Res 1954;33:552-7

3) Harrris R. Biology of children of Hopewood House, Bowral, Australia. 4. Observations on dental caries experience extending over five years (1957-61). J Dent Res 1963;42: 1387-99

4) Available from: http:// www.indianorphanages.net [Last assessed on 2012 December 26]

5) Available from: http://en.wikipedia.org/wiki/. [Last assessed on 2012 December 26]

6) World Health Organization. Oral Health Surveys. 4th ed. Basic Methods, Geneva: WHO; 1997

7) Mazhari F. Ajami B and Ojrati N: Dental treatment needs of 612 year old children in Mashhad, J Mashhad Dental School 2008;32(1):81-86

8) Singh AA. A study of dental caries in school children from rural Haryana. J Ind Soc Pedo Prev Dent 1999;17:24-8

9) Damle SG, Patel AR. Caries prevalence and treatment needs amongst children of Dharavi, Bombay, India. Community Dent Oral Epidemiol 1994;22:62-3

10) Aukland S, Bjelkaroey J. The dental health of school children in Betul district Madhya Pradesh. J Indian Dent Assoc 1982;54:367-9

11) Diangelis AJ, Rojas AJ. Dental caries and periodontal disease in an Indochinese Refugee population. J Dent Res 1982;61: 1233-5

12) Srivastava RP. Prevalence of Periodontal disease in rural school going children of Jhansi. J Indian Dent Assoc 1989;60: $209-10$ 